(C) 1983. The Genetical Society of Great Britain

\title{
HERMAPHRODITISM AND THE SAMPLING-ERROR MODEL
}

\author{
J. T. MANNING \\ Institute of Extension Studies, University of Liverpool, Liverpool U.K.
}

Received 11.vi.82

\section{SUMMARY}

In small dioecious populations there will frequently be a numerical excess of one sex. It is argued that a gene for hermaphroditism will spread in such conditions. The strength of selection for such a gene is inversely proportional to the population number.

\section{INTRODUCTION}

Most higher plants and many animals are hermaphrodites. There are three commonly argued models for the evolution of hermaphroditism:

(a) The low density model (Tomlinson, 1966)-when numbers are low an individual may have difficulty in finding a mate. Every individual a hermaphrodite meets is a potential mate. In a dioecious population, many encounters are between like-sexed individuals.

(b) The resource allocation model (Charnov, Maynard Smith and Bull, 1976) - a hermaphrodite, by allocating its resources partly to male and partly to female functions, is able in some species, to produce more offspring than a single sexed individual.

(c) The sampling-error model (Ghiselin, 1969)-in small populations there will frequently be a numerical excess of one sex. Hermaphroditism prevents such fluctuations.

Although Ghiselin (1969) was able to present comparative evidence that the sampling-error model has some importance, it is difficult to see how it can be formulated in terms of advantage to a gene for hermaphroditism rather than a group advantage (see Maynard Smith, 1978). The purpose of this paper is to argue that a gene for hermaphroditism may spread in a dioecious population if the latter often deviates from a 1:1 sex ratio.

\section{THE MODEL}

Consider a diploid population of dioecious individuals. A rare dominant mutation $H$ arises in generation 1 so that $H /+$ individuals are hermaphrodites which allocate equal resources to male and female gamete production. Let the size of the adult breeding group be $N+1$, and the number of males and females respectively be $\mathrm{Nr}$ and $N(1-r)$. Then the frequency of the $H$ gene is

$$
p_{1}=1 / 2(N+1)
$$

and its expected frequency (conditional on the value of $r$ ) in the next 
generation is

$$
p_{2}=\frac{1}{4}\left\{\frac{1}{2 N r+1}+\frac{1}{2 N(1-r)+1}\right\}
$$

(note that because of the finite population size assumed, the actual frequency of $H$ will deviate from this somewhat).

The expectation of $p_{2}$ taken over all possible values of $r$ is given by

$$
E\left\{p_{2}\right\} \approx \frac{1}{2(N+1)}+\frac{V_{r}}{2}\left(\frac{d^{2} p_{2}}{d r^{2}}\right)_{r=\frac{1}{2}}
$$

where $V_{r}=\frac{1}{4} N$ is the variance in $r$ generated by binomial sampling of the frequency of males, assuming a mean value of $\frac{1}{2}$. Evaluating the derivative, we obtain

$$
E\left\{p_{2}\right\} \approx \frac{1}{2(N+1)}+\frac{N}{2(N+1)^{3}} \approx \frac{1}{2 N+1}+\frac{1}{2 N^{2}}
$$

for large $N$. The strength of selection in favour of $H$ is measured by

$$
\left(E\left\{p_{2}\right\}-p_{1}\right) / p_{1} \approx 1 / N
$$

\section{Discussion}

The advantage sustained by a gene for hermaphroditism in the above model is dependent on an effect first discussed by Fisher (1930) and later by Verner (1965) and Williams (1979). Thus if males are rare within a population, males may have a higher reproductive output than females in the same population. If an individual has produced equal numbers of male and female offspring, then its reproductive gain will be higher than those who have produced an excess of females. The same argument holds if there is an excess of males. This model has been applied to the hermaphrodite case by Borgia and Blick (1981). They show that hermaphrodites produce more offspring than gonochorists in small populations. However, this effect is not related to the spread of a gene for hermaphroditism. Moreover they feel that the advantage produced for hermaphroditism accrues from Tomlinson's low density model (1966). The argument developed here indicates that the low density and sampling-error models may depend on the same underlying effect i.e., random fluctuation in sex ratio.

Acknowledgements.-I am indebted to the referee of this paper for suggestions relating to the form of the model.

\section{REFERENCES}

BORGIA, G. AND BLICK, J. 1981. Sexual competition and the evolution of hermaphroditism, J. Theor. Biol., 89, 523-532.

CHARNOV, E. L., MAYNARD SMITH, J. AND BULL. J. T. 1976. Why be an hermaphrodite? Nature, 263, 125-126.

FISHER, R. A. 1930. The Genetical Theory of Natural Selection. Dover, New York.

GHISELIN, M. T. 1969. The evolution of hermaphroditism among animals. Quart. Rev. Biol., 47, 189-208. 
HERMAPHRODITISM AND THE SAMPLING-ERROR MODEL 93

MAYNARD SMITH, J. 1978. The Evolution of Sex. Cambridge University Press, Cambridge. TOMLINSON, J. 1966. The advantage of hermaphroditism and parthenogenesis. J. Theor. Biol., 11, 54-58.

VERNER, J. 1965. Selection for sex ratio. Amer. Nat., 99, 419-421.

WILLIAMS, G. C. 1979. The question of adaptive sex ratio in outcrossed vertebrates. Proc. R. Socy., 205, 567-580. 